\title{
PENGARUH SISTEM OLAH TANAH DAN APLIKASI HERBISIDA TERHADAP BEBERAPA SIFAT KIMIA TANAH PADA TANAH ULTISOL DI PERTANAMAN UBI KAYU(Manihot esculenta Crantz)
}

\author{
Rusdiyan Inantha, Sarno, Ainin Niswati \& Abdul Kadir Salam \\ Jurusan Agroteknologi, Fakultas Pertanian, Universitas Lampung \\ Jl. Prof. Dr. Soemantri Brojonegoro No.1 Bandar Lampung 35145 Indonesia \\ Email: rusdiyaninantha@yahoo.com
}

\begin{abstract}
ABSTRAK
Ubikayu (Manihot esculenta Crantz) merupakan sumber bahan makanan ketiga di Indonesia setelah padi dan jagung. Secara umum budidaya ubikayu di Indonesia menggunakan sistem pengolahan tanah intensif dan sistem olah tanah minimum juga dapat digunakan sebagai alternatif lain pengganti olah tanah intensif dan pemberantasan gulma menjadi bagian penting dalam sistem olah tanah minimum. Tujuan penelitian ini adalah untuk mengetahui pengaruh sistem olah tanah dan aplikasi herbisida terhadap beberapa sifat kimia tanah, serta interaksi sistem olah tanah dan aplikasi herbisida terhadap beberapa sifat kimia tanah pada tanah Ultisol di pertanaman Ubikayu. Penelitian dilaksanakan di Laboratorium Lapang Terpadu dan di Laboratorium Ilmu Tanah, Fakultas Pertanian, Universitas Lampungdari bulan Juni 2014 sampai April 2015. Penelitian ini disusun dari faktorial 2 x 2 dalam Rancangan Acak Kelompok (RAK). Perlakuan terdiri dari 2 faktor. Faktor pertama terdiri dari 2 perlakuan yaitu sistem olah tanah intensif (OTI) dengan simbol $\mathrm{T}_{1}$ dan olah tanah minimum (OTM) dengan simbol $\mathrm{T}_{0}$. Faktor kedua terdiri dari 2 perlakuan yaitu disemprot dengan herbisida dengan simbol $\mathrm{H}_{1}$ dan tanpa disemprot dengan herbisida dengan simbol $\mathrm{H}_{0}$. Data yang diperoleh diuji dengan uji Bartlett, aditivitas data diuji dengan uji Tukey. Jika asumsi terpenuhi data dianalisis dengan sidik ragam dan perbedaan nilai tengah perlakuan diuji dengan uji Beda Nyata Jujur (BNJ) pada taraf 5\%.Hasil penelitian menunjukan bahwa sistem olah tanah tidak berpengaruh terhadap C-organik, N-total, P-tersedia, K-dd, $\mathrm{pH}$, dan KTK tanah pada 2 waktu pengambilan sampel tanah yaitu 5 BST - 10 BST, kecuali pada waktu awal pengambilan sampel tanah 2 BST berpengaruh terhadap K-dd tanah. Aplikasi herbisida tidak berpengaruh terhadap C-organik, N-total, Ptersedia, K-dd, pH, dan KTK tanah pada 3 waktu pengambilan sampel tanah (2 BST - 5 BST - 10 BST). Sistem olah tanah dan aplikasi herbisida tidak memberikan interaksi yang nyata terhadap sifat kimia tanah yaitu C-organik, N-total, P-tersedia, K-dd, $\mathrm{pH}$, dan KTK tanah.
\end{abstract}

Kata kunci: herbisida, kimia tanah, sistem olah tanah

\section{PENDAHULUAN}

Ubikayu (Manihot esculenta Crantz) merupakan sumber bahan makanan ketiga di Indonesia setelah padi dan jagung (Barret dan Damardjati, 1984). Pada sistem budidaya ubikayu, sebagian besar sentra produksi ubikayu berada di lahan kering dengan jenis tanah Alfisol, Ultisol, dan Inceptisol yang umumnya mempunyai tingkat kesuburan rendah (Suryana, 2007). Berdasarkan keadaan yang ada, maka salah satu alternatif untuk mengantisipasi masalah tersebut yaitu dengan pengelolaan yang tepat untuk meningkatkan kualitas tanah sehingga kerusakan tanah dapat dicegah (Pramudita, 2014).

Secara umum budidaya ubikayu di Indonesia menggunakan sistem pengolahan tanah intensif yang bertujuan untuk memicu kecepatan dekomposisi bahan organik, sehingga akan mempengaruhi tingkat kesuburan dan produktivitas tanah dan menyebabkan aerasi dan drainase menjadi lebih baik dan temperatur tanah juga meningkat (Fuady, 2010). Pengolahan tanah yang terus menerus secara sempurna (intensif) mengakibatkan tingkat pencuciaan (Musa dkk., 2007) dan erosi akan sangat tinggi dan berdampak pada pertumbuhan tanaman (Fuady, 2010). Oleh sebab itu sistem olah tanah minimum juga dapat digunakan sebagai alternatif lain pengganti olah tanah intensif.

Pemberantasan gulma menjadi bagian penting dalam sistem olah tanah minimum. Pengendalian gulma dapat dilakukan secara manual dan pengendalian gulma dapat pula dilakukan menggunakan herbisida.Adnan (2012) menjelaskan bahwa gulma yang mati akibat penyemprotan herbisida dan pengolahan tanah akan mengalami pelapukan dan mineralisasi menjadi unsur hara yang tersedia untuk diserap oleh tanaman dan penelitian ini dilakukan pada pertanaman ubikayu yang dianggap sebagai tanaman yang rakus hara yang dapat memiskinkan tanah. Hal ini didasarkan pada salah satu sifat ubikayu yang sangat efisien menyerap hara pada berbagai kondisi tanah (Radjit dkk., 2014). 
Tujuan penelitian ini adalah untuk mengetahui pengaruh sistem olah tanah dan aplikasi herbisida terhadap beberapa sifat kimia tanah, serta interaksi sistem olah tanah dan aplikasi herbisida terhadap beberapa sifat kimia tanah pada tanah Ultisol di pertanaman Ubikayu.

\section{BAHAN DAN METODE}

Penelitian ini dilaksanakan pada Juni 2014 hingga April 2015. Penelitian ini dilaksanakan pada pertanaman Ubikayu di Laboratorium terpadu Fakultas Pertanian Universitas Lampung dan analisis tanah dilakukan di Laboratorium Ilmu Tanah Fakultas Pertanian Universitas Lampung.

Alat-alat yang digunakan pada penelitian ini yaitu sekop, plastik, ayakan $2 \mathrm{~mm}$, label dan alat-alat laboratorium untuk analisis C-organik tanah, N, P, K tanah, pH tanah, Kapasitas Tukar Kation (KTK) tanah. Sedangkan bahan - bahan yang digunakan yaitu sampel tanah ultisol di Gedong Meneng Bandar Lampung serta bahan - bahan untuk analisis tanah.

Penelitian ini disusun dari faktorial 2 × 2 dalam Rancangan Acak Kelompok (RAK). Perlakuan terdiri dari 2 faktor. Faktor pertama terdiri dari 2 perlakuan yaitu sistem olah tanah intensif (OTI) dengan simbol $\mathrm{T}_{1}$ dan olah tanah minimum (OTM) dengan simbol $\mathrm{T}_{0}$. Faktor kedua terdiri dari 2 perlakuan yaitu disemprot dengan herbisida dengan simbol $\mathrm{H}_{1}$ dan tanpa disemprot dengan herbisida dengan simbol $\mathrm{H}_{0}$

Pelaksanaan Penelitian. Tanah percobaan pernah ditanami jagung dengan perlakuan yang sama pada bulan Maret - Juni 2014. Setelah itu, pada bulan juni 2014 ditanami dengan Ubi kayu (penelitian ini).

Petak percobaan dibuat secara berkelompok yaitu empat perlakuan pengolahan tanah dan pemberian herbisida. Lahan penelitian dibagi menjadi 16 petak dengan ukuran setiap petaknya $3 \mathrm{~m} \times 4 \mathrm{~m}$ yang ditanami oleh tanamam ubi kayu dengan jarak tanam $90 \times 50 \mathrm{~cm}$. Tanaman ubi kayu ini dipupuk dengan pupuk Urea $200 \mathrm{~kg}$ $\mathrm{ha}^{-1}$, SP-36 $300 \mathrm{~kg} \mathrm{ha}^{-1}$, KCL $300 \mathrm{~kg} \mathrm{ha}^{-1}$ dan Organonitrofos $10.000 \mathrm{~kg} \mathrm{ha}^{-1}$. Pupuk urea diberikan dua kali yaitu setengah dosis pada saat tanaman ubi kayu berumur satu minggu dan selanjutnya diberikan pada saat tanaman berumur 6 bulan.

Pelaksanaan Percobaan di Lapang. Pada perlakuan sistem olah tanah yaitu OTI $\left(\mathrm{T}_{1}\right)$ tanah dicangkul dan tanah dibalik secara merata dan OTM $\left(\mathrm{T}_{0}\right)$ tanah dicangkul seperlunya saja. Pada perlakuan pengendalian gulma yaitu $\left(\mathrm{H}_{1}\right)$ gulma disemprot dengan herbisida yang berbahan aktif Isopropilamina glifosat $240 \mathrm{~g} / \mathrm{l}$ dengan dosis $160 \mathrm{ml} / 16$ liter air (tanki) dan tanpa herbisida $\left(\mathrm{H}_{0}\right)$ gulma tidak disemprot. Perlakuan yang didapat yaitu (1) $\mathrm{T}_{1} \mathrm{H}_{1}=$ OTI dan gulma disemprot lalu gulma yang mati dibuang keluar petak percobaan (2) $\mathrm{T}_{1} \mathrm{H}_{0}=\mathrm{OTI}$ dan gulma dikoret lalu gulma dibuang keluar petak percobaan (3) $\mathrm{T}_{0} \mathrm{H}_{1}=$ OTM dan gulma disemprot lalu gulma dibiarkan di dalam petak percobaan (4) $\mathrm{T}_{0} \mathrm{H}_{0}$ $=$ OTM dan gulma dikoret lalu gulma dibiarkan di dalam petak percobaan.

Pengambilan sampel tanah dilakukan 2 bulan setelah tanaman (BST) (Agustus 2014), 5 BST (November 2014) dan 10 BST (April 2015). Pengambilan sampel tanah dilakukan 2 bulan setelah tanaman (BST) (Agustus 2014), 5 BST (November 2014) dan 10 BST (April 2015). Sampel tanah diambil dari lima titik dan diambil secara diagonal kemudian diaduk menjadi satu (komposit). Tanah pada penelitian ini diambil dari lahan yang merupakan tanah ultisol yang sedang ditanami tanaman ubikayu dengan kedalaman $0-20 \mathrm{~cm}$.

Variabel yang diamati adalah C-organik tanah (Walkey \& Black), Nitrogen tanah (Kjeldhal), Fosfor tanah (Bray I), Kalium tanah, $\mathrm{pH}$ tanah (pH meter) dan Kapasitas Tukar Kation (KTK) tanah (Asam Asetat pH 7).

Data yang diperoleh diuji dengan uji Bartlett, aditivitas data diuji dengan uji Tukey. Jika asumsi terpenuhi data dianalisis dengan sidik ragam dan perbedaan nilai tengah perlakuan diuji dengan uji Beda Nyata Jujur (BNJ) pada taraf 5\%.

\section{HASIL DAN PEMBAHASAN}

Hasil penelitian menunjukan bahwa sistem olah tanah dan aplikasi herbisida tidak berpengaruh terhadap kandungan C-organik pada tanah Ultisol. Kandungan C-organik tanah (Tabel 1) diharapkan dapat meningkat akibat dari penambahan bahan organik dari sisa-sisa gulma yang mati dan tetap berada di lahan, akan tetapi kenyataannya tidak.

Analisis ragam menunjukan bahwa kandungan Corganik (Tabel 1) pada perlakuan $\mathrm{T}_{0} \mathrm{H}_{0}$ (olah tanah minimum + tanpa herbisida), $\mathrm{T}_{0} \mathrm{H}_{1}$ (olah tanah minimum + herbisida), $\mathrm{T}_{1} \mathrm{H}_{0}$ (olah tanah intensif + tanpa herbisida) dan $\mathrm{T}_{1} \mathrm{H}_{1}$ (olah tanah intensif + herbisida) pada lahan penelitian ini tidak berpengaruh terhadap kandungan $\mathrm{C}$ organik tanah yang mungkin disebabkan oleh minimnya gulma yang terdapat pada lahan penelitian tersebut atau bahan organik yang belum terdekomposisi secara keseluruhan menjadi C-organik dan unsur hara lainnya. Leomo dkk (2013) menjelaskan bahwa penurunan Corganik tanah juga dapat disebabkan oleh kurangnya suplai bahan organik yang berasal dari serasah tanaman 
yang di atasnya terdekomposisi dan menurut penelitian Supriyadi (2008) temperatur juga mempengaruhi kecepatan dekomposisi bahan organik.

Pengaruh Sistem Olah Tanah dan Aplikasi Herbisida terhadap N-Total Tanah. Hasil analisis ragam menunjukan bahwa sistem olah tanah dan aplikasi herbisida serta interaksinya tidak berpengaruh terhadap kandungan $\mathrm{N}$-total tanah baik pada pada $2 \mathrm{BST}$, maupun 5 BST dan 10 BST (Tabel 2).

Kandungan N-total tanah pada waktu awal pengambilan sampel tanah 2 BST termasuk dalam kriteria rendah yaitu dengan perlakuan olah tanah minimum dan tanpa herbisida $\left(\mathrm{T}_{0} \mathrm{H}_{0}\right)$, olah tanah minimum dan aplikasi herbisida $\left(\mathrm{T}_{0} \mathrm{H}_{1}\right)$, olah Tanah Intensif dan tanpa herbisida $\left(\mathrm{T}_{1} \mathrm{H}_{0}\right)$ dan olah tanah intensif dan aplikasi herbisida $\left(\mathrm{T}_{1} \mathrm{H}_{1}\right)$. Pada waktu pengambilan 5 BST dan $10 \mathrm{BST}$ kandungan $\mathrm{N}$-total tanah tidak mengalami peningkatan yang nyata (Tabel 2).
Dengan demikian terlihat bahwa sistem olah tanah dan aplikasi herbisida tidak berpengaruh terhadap kandungan $\mathrm{N}$-total tanah pada lahan penelitian ini. Hal ini dapat saja disebabkan karena rendahnya kandungan $\mathrm{C}$-organik yang ada pada lahan tersebut. Menurut penelitian Antari dkk (2012) menjelaskan bahwa kandungan $\mathrm{N}$ di dalam tanah dapat dipengaruhi oleh kadar C-organik karena peningkatan nitrogen dalam tanah merupakan akibat dari penambahan unsur tersebut yang terkandung dalam mulsa organik oleh sebab itu semakin tinggi bahan organik tanah maka semakin tinggi pula nilai $\mathrm{N}$-total tanah.

Pengaruh Sistem Olah Tanah dan Aplikasi Herbisida terhadap P-Tersedia Tanah. Hasil analisis ragam menunjukan bahwa sistem olah tanah dan aplikasi herbisida serta interaksinya tidak berpengaruh terhadap kandungan P-tersedia tanah baik pada 2 BST maupun 5 BST dan 10 BST (Tabel3).

Tabel 1. Pengaruh sistem olah tanah dan aplikasi herbisida terhadap C-organik tanah pada tanah Ultisol di pertanaman ubikayu.

\begin{tabular}{|c|c|c|c|}
\hline \multirow{2}{*}{ Perlakuan } & \multicolumn{3}{|c|}{ Waktu Pengamatan } \\
\hline & $2 \mathrm{BST}$ & $5 \mathrm{BST}$ & $10 \mathrm{BST}$ \\
\hline & \multicolumn{3}{|c|}{ 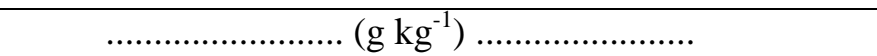 } \\
\hline $\mathrm{T}_{0} \mathrm{H}_{0}$ & 15,9 & 14,2 & 11,6 \\
\hline $\mathrm{T}_{0} \mathrm{H}_{1}$ & 16,7 & 13,2 & 9,9 \\
\hline $\mathrm{T}_{1} \mathrm{H}_{0}$ & 15,5 & 13,8 & 12,2 \\
\hline $\mathrm{T}_{1} \mathrm{H}_{1}$ & 17,3 & 16,7 & 11,2 \\
\hline Sumber Keragaman & \multicolumn{3}{|c|}{ Signifikansi } \\
\hline $\mathrm{T}$ & tn & tn & tn \\
\hline $\mathrm{H}$ & tn & tn & tn \\
\hline TxH & tn & tn & tn \\
\hline
\end{tabular}

Keterangan : $\mathrm{T}=$ Sistem Olah Tanah; $\mathrm{H}=$ Aplikasi Herbisida; $\mathrm{T}_{0}=$ Olah Tanah Minimum $; \mathrm{T}_{1}=$ Olah Tanah Intesif ; $\mathrm{H}_{0}=$ Tanpa Aplikasi Herbisida ; $\mathrm{H}_{1}=$ Aplikasi Herbisida; $B S T=B u l a n$ Setelah Tanam. $*=$ berbeda nyata pada taraf $5 \%, \mathrm{tn}=$ tidak berbeda nyata pada taraf $5 \%$

Tabel 2. Pengaruh sistem olah tanah dan aplikasi herbisida terhadap N-total pada tanah Ultisol di pertanaman ubikayu.

\begin{tabular}{|c|c|c|c|}
\hline \multirow{2}{*}{ Perlakuan } & \multicolumn{3}{|c|}{ Waktu Pengamatan } \\
\hline & $2 \mathrm{BST}$ & $5 \mathrm{BST}$ & $10 \mathrm{BST}$ \\
\hline & \multicolumn{3}{|c|}{ 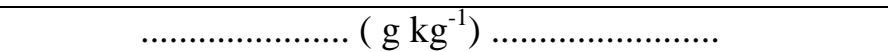 } \\
\hline $\mathrm{T}_{0} \mathrm{H}_{0}$ & 1,3 & 1,5 & 1,6 \\
\hline $\mathrm{T}_{0} \mathrm{H}_{1}$ & 1,3 & 1,4 & 1,5 \\
\hline $\mathrm{T}_{1} \mathrm{H}_{0}$ & 1,1 & 1,4 & 1,5 \\
\hline $\mathrm{T}_{1} \mathrm{H}_{1}$ & 1,2 & 1,4 & 1,5 \\
\hline Sumber Keragaman & \multicolumn{3}{|c|}{ Signifikansi } \\
\hline $\mathrm{T}$ & tn & tn & tn \\
\hline $\mathrm{H}$ & tn & tn & tn \\
\hline TxH & tn & tn & tn \\
\hline
\end{tabular}

Keterangan : $\mathrm{T}=$ Sistem Olah Tanah; $\mathrm{H}=$ Aplikasi Herbisida; $\mathrm{T}_{0}=$ Olah Tanah Minimum ; $\mathrm{T}_{1}=$ Olah Tanah Intesif ; $\mathrm{H}_{0}=$ Tanpa Aplikasi Herbisida $; \mathrm{H}_{1}=$ Aplikasi Herbisida; BST=Bulan Setelah Tanam. $*=$ berbeda nyata pada taraf $5 \%, \mathrm{tn}=$ tidak berbeda nyata pada taraf $5 \%$ 
Kandungan P-tersedia tanah pada waktu awal pengambilan sampel tanah 2 BST termasuk dalam kriteria rendah yaitu dengan perlakuan $\mathrm{T}_{0} \mathrm{H}_{0}, \mathrm{~T}_{0} \mathrm{H}_{1}, \mathrm{~T}_{1} \mathrm{H}_{0}$, dan $\mathrm{T}_{1} \mathrm{H}_{1}$ dan pada waktu pengambilan kedua 5 BST dan ketiga 10 BST kandungan P-tersedia termasuk dalam kriteria sedang (Tabel 3).

Kandungan P-tersedia tanah (Tabel 3) jika diperhatikan dari 2 BST, P-tersedia meningkat pada 5 BST dan 10 BST. Kandungan P-tersedia (Tabel 3) pada 2 BST masih termasuk dalam kriteria rendah, hal ini dapat saja diakibatkan dari terangkutnya unsur hara $\mathrm{P}$ oleh tanaman pada saat musim tanam pertama. Nugroho dkk (2013) menjelaskan dalam penelitiannya bahwa penurunan $\mathrm{P}$ karena pencucian hara, terangkutnya oleh tanaman, subsiden atau pemadatan dan rendahnya nilai $\mathrm{pH}$. Sedangkan peningkatan kandungan P-tersedia terjadi pada 5 BST dan 10 BST diduga karena pengaruh olah tanah intensif dan gulma yang mati akibat dari aplikasi herbisida. Utami dan Handayani (2003) menambahkan peningkatan P-tersedia dapat terjadi karena pelepasan $\mathrm{P}$ dari bahan organik yang ditambahkan. Namun, berdasarkan analisis ragam (Tabel 3) sistem olah tanah dan aplikasi herbisida masih dapat dikatakan tidak berpengaruh terhadap P-tersedia tanah pada lahan penelitian tersebut.

Pengaruh Sistem Olah Tanah dan Aplikasi Herbisida terhadap K-dd Tanah. Hasil analisis ragam menunjukan bahwa sistem olah tanah berpengaruh terhadap kandungan K-dd tanah pada 2 BST (Tabel 4) dan pada 5 BST dan 10 BST (Tabel4) sistem olah tanah dan aplikasi herbisida serta interaksinya tidak berpengaruh terhadap kandungan K-dd tanah.

Tabel 4 menunjukan bahwa kandungan K-dd tanah pada awal pengambilan sampel tanah 2 BST

Tabel 3. Pengaruh sistem olah tanah dan aplikasi herbisida terhadap P-tersedia Tanah pada tanah Ultisol di pertanaman ubikayu.

\begin{tabular}{|c|c|c|c|}
\hline \multirow{2}{*}{ Perlakuan } & \multicolumn{3}{|c|}{ Waktu Pengamatan } \\
\hline & $2 \mathrm{BST}$ & $5 \mathrm{BST}$ & $10 \mathrm{BST}$ \\
\hline & \multicolumn{3}{|c|}{ 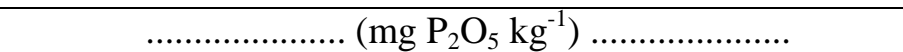 } \\
\hline $\mathrm{T}_{0} \mathrm{H}_{0}$ & 6,14 & 8,51 & 8,54 \\
\hline $\mathrm{T}_{0} \mathrm{H}_{1}$ & 4,11 & 8,69 & 8,26 \\
\hline $\mathrm{T}_{1} \mathrm{H}_{0}$ & 5,03 & 8,81 & 8,35 \\
\hline $\mathrm{T}_{1} \mathrm{H}_{1}$ & 5,00 & 8,90 & 8,18 \\
\hline Sumber Keragaman & \multicolumn{3}{|c|}{ Signifikansi } \\
\hline $\mathrm{T}$ & tn & tn & th \\
\hline $\mathrm{H}$ & tn & $\operatorname{tn}$ & th \\
\hline TxH & tn & tn & tn \\
\hline
\end{tabular}

Keterangan : $\mathrm{T}=$ Sistem Olah Tanah; $\mathrm{H}=$ Aplikasi Herbisida; $\mathrm{T}_{0}=$ Olah Tanah Minimum $; \mathrm{T}_{1}=$ Olah Tanah Intesif $; \mathrm{H}_{0}=$ Tanpa Aplikasi Herbisida ; $\mathrm{H}_{1}=$ Aplikasi Herbisida; BST=Bulan Setelah Tanam. $*=$ berbeda nyata pada taraf $5 \%, \mathrm{tn}=$ tidak berbeda nyata pada taraf $5 \%$

Tabel 4. Pengaruh sistem olah tanah dan aplikasi herbisida terhadap K-dd Tanah pada tanah Ultisol yang ditanami ubikayu.

\begin{tabular}{cccc}
\hline \multirow{2}{*}{ Perlakuan } & \multicolumn{3}{c}{ Waktu Pengamatan } \\
\cline { 2 - 4 } & $2 \mathrm{BST}$ & $5 \mathrm{BST}$ & $10 \mathrm{BST}$ \\
\hline & 0,74 & 0,81 & 0,30 \\
$\mathrm{~T}_{0} \mathrm{H}_{0}$ & 0,64 & 0,42 & 0,55 \\
$\mathrm{~T}_{0} \mathrm{H}_{1}$ & 0,39 & 0,24 \\
$\mathrm{~T}_{1} \mathrm{H}_{0}$ & 0,52 & 0,28 & 0,25 \\
$\mathrm{~T}_{1} \mathrm{H}_{1}$ & 0,51 & Signifikansi k & \\
\hline Sumber Keragaman & & tn & tn \\
\hline $\mathrm{T}$ & $*$ & tn & tn \\
\hline $\mathrm{H}$ & tn & tn & tn
\end{tabular}

Keterangan : $\mathrm{T}=$ Sistem Olah Tanah; $\mathrm{H}=$ Aplikasi Herbisida; $\mathrm{T}_{0}=$ Olah Tanah Minimum; $\mathrm{T}_{1}=$ Olah Tanah Intesif ; $\mathrm{H}_{0}=$ Tanpa Aplikasi Herbisida $; \mathrm{H}_{1}=$ Aplikasi Herbisida; BST=Bulan Setelah Tanam. $*=$ berbeda nyata pada taraf $5 \%, \mathrm{tn}=$ tidak berbeda nyata pada taraf $5 \%$ 
bervariasi, yaitu $\mathrm{T}_{0} \mathrm{H}_{0}$ dan $\mathrm{T}_{0} \mathrm{H}_{1}$ termasuk dalam kriteria tinggi sedangkan $\mathrm{T}_{1} \mathrm{H}_{0}$ dan $\mathrm{T}_{1} \mathrm{H}_{1}$ termasuk dalam kriteria sedang. Pada sampel pengambilan kedua 5 BST dan ketiga 10 BST kandungan K-dd termasuk dalam kriteria sedang dan rendah (Tabel 4).

Kandungan K-dd (Tabel 4) tinggi pada 2 BST dan 5 BST dengan perlakuan $\mathrm{T}_{0} \mathrm{H}_{0}$ dan $\mathrm{T}_{0} \mathrm{H}_{1}$. Sesuai dengan hasil penelitian Adnan (2012) bahwa peningkatan K-dd tanah tidak terlepas dari sumbangan sejumlah unsur hara khususnya kalium yang dihasilkan dari gulma yang mati akibat penyemprotan herbisida, dan pada 10 BST kandungan K-dd tanah (Tabel 4) menurun.

Dengan demikian terlihat bahwa sistem olah tanah dan aplikasi herbisida tidak berpengaruh terhadap kandungan K-dd tanah pada 5 BST dan 10 BST pada lahan penelitian kecuali perlakuan sistem olah tanah pada awal pengambilan yaitu 2 BST berpengaruh terhadap kandungan K-dd tanah (Tabel 4) dan kandungan K-dd dalam tanah dari perlakuan sistem olah tanah yaitu olah tanah minimum dan olah tanah intensif tidak berbeda nyata pada waktu pengamatan 2 BST (Tabel 5).

Pengaruh Sistem Olah Tanah dan Aplikasi Herbisida terhadap pH Tanah. Hasil analisis ragam menunjukan bahwa sistem olah tanah dan aplikasi herbisida serta interaksinya tidak berpengaruh terhadap kandungan $\mathrm{pH}$ tanah baik pada 2 BST, maupun 5 BST dan 10 BST (Tabel6).

Tabel 6 menunjukan bahwa pH tanah pada waktu awal pengambilan sampel tanah 2 BST sampai dengan waktu pengambilan ketiga bulan April 2105 termasuk dalam kriteria Agak Masam yaitu pada waktu pengambilan awal dengan perlakuan $\mathrm{T}_{0} \mathrm{H}_{0}, \mathrm{~T}_{0} \mathrm{H}_{1}, \mathrm{~T}_{1} \mathrm{H}_{0}$ dan $\mathrm{T}_{1} \mathrm{H}_{1}$. Pada waktu pengambilan kedua dan ketiga tidak menunjukan perubahan (Tabel 6).

Analisis ragam (Tabel 6) menunjukan bahwa sistem olah tanah dan aplikasi herbisida tidak berpengaruh terhadap nilai $\mathrm{pH}$ pada lahan penelitian tersebut. Nilai $\mathrm{pH}$ tanah (Tabel 6) pada penelitian ini termasuk dalam kriteria Agak Masam. Hal ini terjadi karena tanah penelitian termasuk dalam kriteria tanah ultisol yang sebagian besar memiliki nilai $\mathrm{pH}$ cukup rendah atau masam. Selain faktor tersebut menurut penelitian Zulkarnain (2014) menjelaskan menurunnya pH tanah dapat disebabkan oleh meningkatnya kadar asam bahan organik dan menurunnya kation basa akibat diserap olah tanaman dan dijelaskan pula dalam penelitian Harsono (2011) bahwa peningkatan $\mathrm{pH}$ tanah terjadi apabila bahan organik terdekomposisi sempurna.

Pengaruh Sistem Olah Tanah dan Aplikasi Herbisida terhadap KTK Tanah. Hasil analisis ragam

Tabel 5. Pengaruh sistem olah tanah terhadap kandungan K-dd tanah pada 2 BST

\begin{tabular}{cc}
\hline Perlakuan & $\begin{array}{c}\text { K-dd tanah } \\
\left(\mathrm{cmol} \mathrm{kg}^{-1}\right)\end{array}$ \\
\hline $\mathrm{T}_{0}$ & $0,69 \mathrm{a}$ \\
$\mathrm{T}_{1}$ & $0,51 \mathrm{a}$ \\
\hline BNJ 5\% & 0,21 \\
\hline
\end{tabular}

Keterangan: Nilai tengah yang diikuti dengan huruf yang berbeda, berbeda nyata berdasarkan uji BNJ pada taraf $5 \%$

Tabel 6. Pengaruh sistem olah tanah dan aplikasi herbisida terhadap $\mathrm{pH}$ Tanah pada tanah Ultisol di pertanaman ubikayu.

\begin{tabular}{cccc}
\hline \multirow{2}{*}{ Perlakuan } & \multicolumn{3}{c}{ Waktu Pengamatan } \\
\cline { 2 - 4 } & 2 BST & 5 BST & 10 BST \\
\hline $\mathrm{T}_{0} \mathrm{H}_{0}$ & 6,33 & 6,51 & 6,26 \\
$\mathrm{~T}_{0} \mathrm{H}_{1}$ & 6,24 & 6,21 & 6,15 \\
$\mathrm{~T}_{1} \mathrm{H}_{0}$ & 6,27 & 6,37 & 6,18 \\
$\mathrm{~T}_{1} \mathrm{H}_{1}$ & 6,27 & 6,48 & 5,95 \\
\hline Sumber Keragaman & & Signifikansi & tn \\
$\mathrm{T}$ & tn & tn & tn \\
TxH & tn & tn & tn \\
\hline
\end{tabular}

Keterangan : $\mathrm{T}=$ Sistem Olah Tanah; $\mathrm{H}=$ Aplikasi Herbisida; $\mathrm{T}_{0}=$ Olah Tanah Minimum $; \mathrm{T}_{1}=$ Olah Tanah Intesif ; $\mathrm{H}_{0}=$ Tanpa Aplikasi Herbisida $; \mathrm{H}_{1}=$ Aplikasi Herbisida; $\mathrm{BST}=$ Bulan Setelah Tanam. $*=$ berbeda nyata pada taraf $5 \%, \mathrm{tn}=$ tidak berbeda nyata pada taraf $5 \%$ 
Tabel 7. Pengaruh sistem olah tanah dan aplikasi herbisida terhadap KTK Tanah pada tanah Ultisol di pertanaman ubikayu.

\begin{tabular}{cccc}
\hline \multirow{2}{*}{ Perlakuan } & \multicolumn{3}{c}{ Waktu Pengamatan } \\
\cline { 2 - 4 } & $2 \mathrm{BST}$ & $5 \mathrm{BST}$ & $10 \mathrm{BST}$ \\
\hline & 7,48 & 7,13 & \\
$\mathrm{~T}_{0} \mathrm{H}_{0}$ & 7,73 & 6,10 & 6,55 \\
$\mathrm{~T}_{0} \mathrm{H}_{1}$ & 7,58 & 6,78 & 6,65 \\
$\mathrm{~T}_{1} \mathrm{H}_{0}$ & 7,93 & Signifikansi & 7,28 \\
$\mathrm{~T}_{1} \mathrm{H}_{1}$ & & tn & 6,83 \\
\hline Sumber Keragaman & tn & tn & tn \\
$\mathrm{T}$ & tn & tn & tn \\
TxH & tn & tn \\
\hline
\end{tabular}

Keterangan : $\mathrm{T}=$ Sistem Olah Tanah; $\mathrm{H}=$ Aplikasi Herbisida; $\mathrm{T}_{0}=$ Olah Tanah Minimum $; \mathrm{T}_{1}=$ Olah Tanah Intesif $; \mathrm{H}_{0}=$ Tanpa Aplikasi Herbisida $; \mathrm{H}_{1}=$ Aplikasi Herbisida; $\mathrm{BST}=$ Bulan Setelah Tanam. $*=$ berbeda nyata pada taraf $5 \%, \mathrm{tn}=$ tidak berbeda nyata pada taraf $5 \%$

menunjukan bahwa sistem olah tanah dan aplikasi herbisida serta interaksinya tidak berpengaruh terhadap kandungan KTK tanah baik pada 2 BST, maupun 5 BST dan 10 BST (Tabel7).

Tabel 7 menunjukan nilai KTK tanah pada tanah waktu awal pengambilan sampel tanah sampai dengan waktu pengambilan sampel ketiga termasuk dalam kriteria rendah yaitu bulan Agustus dengan perlakuan $\mathrm{T}_{0} \mathrm{H}_{0}, \mathrm{~T}_{0} \mathrm{H}_{1}, \mathrm{~T}_{1} \mathrm{H}_{0}$ dan $\mathrm{T}_{1} \mathrm{H}_{1}$. Serta nilai KTK tanah pada pengambilan sampel kedua dan ketiga tidak memiliki perbedaan yang begitu besar (Tabel 7).

Analisis ragam (Tabel 7) menunjukan sistem olah tanah dan aplikasi herbisida tidak berpengaruh terhadap kandungan KTK tanah (Tabel 7) pada lahan penelitian ini hal ini dapat dikarenakan akibat nilai $\mathrm{pH}$ tanah yang yang termasuk dalam kategori agak masam. Menurut Rusdiana dan Lubis (2012) bahwa nilai kapasitas tukar kation yang tinggi dipengaruhi oleh $\mathrm{pH}$ tanah dan ketersediaan bahan organik. Semakin tinggi bahan organik maka semakin tinggi nilai tanahnya.

\section{KESIMPULAN}

Dari hasil penelitian dapat disimpulkan bahwa sistem olah tanah tidak berpengaruh terhadap C-organik, $\mathrm{N}$-total, P-tersedia, K-dd, pH, dan KTK tanah pada 2 waktu pengambilan sampel tanah yaitu 5 BST - 10 BST, kecuali pada waktu awal pengambilan sampel tanah 2 BST berpengaruh terhadap K-dd tanah. Aplikasi herbisida tidak berpengaruh terhadap C-organik, $\mathrm{N}$-total, P-tersedia, K-dd, pH, dan KTK tanah pada 3 waktu pengambilan sampel tanah (2 BST - 5 BST - $10 \mathrm{BST}$ ). Sistem olah tanah dan aplikasi herbisida tidak memberikan interaksi yang nyata terhadap sifat kimia tanah yaitu C-organik, N-total, P-tersedia, K-dd, pH, dan KTK tanah.

\section{DAFTAR PUSTAKA}

Adnan. 2012. Aplikasi beberapa dosis herbisida glifosat dan paraquat pada sistem tanpa olah tanah (TOT) serta pengaruhnya terhadap sifat kimia tanah, karakteristik gulma dan hasil kedelai. J. Agrista 16 (3) : 135-145.

Antari, R., Wawan, dan G.ME. Manurung. 2012. Pengaruh Mulsa Organik Terhadap Sifat Fisik dan Kimia Tanah serta Pertumbuhan Akar Kelapa Sawit. Jurusan Agroteknologi, Fakultas Pertanian. Universitas Riau. $13 \mathrm{hlm}$.

Bareet, M.D. dan S.D. Damardjati. 1984. Peningkatan Mutu Hasil Ubi Kayu di Indonesia. Jakarta.

Fuady, Z. 2010. Pengaruh sistem olah tanah dan residu tanaman terhadap laju mineralisasi nitrogen tanah. J. Ilmiah Sains dan Teknologi. 10(1): 94-101.

Harsono, P. 2011. Mulsa organik: pengaruhnya terhadap lingkungan mikro, sifat kimia tanah dan keragaman cabai merah di vertisol pada musim kemarau. Prosiding Seminar Nasional PERHORTI, Lembang, hlm: 122-129.

Leomo, S., L. Mudi, dan S. Alam. 2013. Aplikasi rizobakteri pada cover crop dalam mempengaruhi sifat kimia tanah tanah bekas tambang nikel. J. Agroteknologi. 3(1): 26-33. 
Musa, Y. 2007. Evaluasi produktivitas jagung melalui pengelolaan populasi tanaman, pengolahan tanah dan dosis pemupukan. J. Agrisistem: 3(1): 21-33.

Nugroho, T.C. 2013. Analisis sifat kimia tanah gambut yang dikonversi menjadi perkebunan kelapa sawit di kabupaten kampar. J. Agroteknologi. 4(1): 25-30.

Prihandana, R., K. Noerwijan, P.G. Adinurani, D. Setyaningsih, S. Setiadi, dan R. Hendroko. 2007. Bioetanol Ubi Kayu Bahan Bakar Masa Depan. Agromedia. Jakarta. $224 \mathrm{hlm}$.

Radjit, B.S., Y. Widodo., N. Saleh, dan N. Prasetiaswati. 2014. Teknologi untuk meningkatkan produktivitas dan keuntungan usahatani ubikayu di lahan kering ultisol. Iptek Tanaman Pangan 9(1): 51-62.

Rusdiana, O. dan R.S. Lubis. 2012. Pendugaan korelasi antara karakteristik tanah terhadap cadangan karbon (carbon stock) pada hutan sekunder. J. Silvikultur Tropika. 3(1): 14-21.

Supriyadi, S. 2008. Kandungan bahan organik sebagai dasar pengelolaan tanah di lahan kering madura. J. Embryo 5(2): 176-183.

Suryana, A. 2007. Kebijakan penelitian dan pengembangan ubi kayu untuk agroindustri dan ketahanan pangan. Prosiding: Prospek, Strategi, dan Teknologi, Pengembangan Ubi kayu untuk Agroindustri dan Ketahanan Pangan. Pusat Penelitian dan Pengembangan Tanaman Pangan. Bogor, hlm: 1-19.

Utami, S.R. dan S. Handayani. 2003. Sifat kimia tanah pada sistem pertanian organik. J. Ilmu Pertanian. 10(2): 63-69.

Zulkarnain. 2014. Perubahan beberapa sifat kimia tanah akibat pemberian limbah cair industri kelapa sawit dengan metode land aplication. J. Agrifor. 8(1): 125-130. 